\title{
CORRECTION
}

View Article Online

View Journal I View Issue

\section{Correction: Tetraaryl pyrenes: photophysical properties, computational studies, crystal structures, and application in OLEDs}

Cite this: J. Mater. Chem. C, 2016, 4, 3059

Tarek H. El-Assaad, ${ }^{a}$ Manuel Auer, ${ }^{\text {b }}$ Raul Castañeda, ${ }^{c}$ Kassem M. Hallal, ${ }^{a}$ Fadi M. Jradi, ${ }^{a}$ Lorenzo Mosca, ${ }^{d}$ Rony S. Khnayzer, ${ }^{e}$ Digambara Patra, ${ }^{a}$ Tatiana V. Timofeeva, ${ }^{c}$ Jean-Luc Brédas, ${ }^{f}$ Emil J. W. List-Kratochvil, ${ }^{\text {bg }}$ Brigitte Wex $^{\star e}$ and Bilal R. Kaafarani ${ }^{\star a}$

DOI: $10.1039 / \mathrm{c} 6 \mathrm{tc} 90031 \mathrm{c}$

Correction for 'Tetraaryl pyrenes: photophysical properties, computational studies, crystal structures, and

www.rsc.org/MaterialsC application in OLEDs' by Tarek H. El-Assaad et al., J. Mater. Chem. C, 2016, DOI: 10.1039/c5tc02849c.

The $x$ coordinate for compound 3 in Table 7 is missing and only the $y$ coordinate is given. The correct coordinates are $0.148,0.243$ and the correct version of this table is as follows:

Table 7 Electroluminescent characteristics of the investigated compounds in a single-layer geometry

\begin{tabular}{|c|c|c|c|c|}
\hline Compound & $V_{\mathrm{on}}{ }^{a}[\mathrm{~V}]$ & $L_{\max }\left[\mathrm{cd} \mathrm{m}^{-2}\right]$ & $H^{b}\left[\mathrm{~cd} \mathrm{~A}^{-1}\right]$ & CIE1931 $[x, y]$ \\
\hline 2 & 2.8 & 13542 & 2.0000 & $0.163,0.200$ \\
\hline 3 & 2.9 & 6902 & 2.6000 & $0.148,0.243$ \\
\hline 4 & 2.9 & 85 & 0.0050 & $0.148,0.244$ \\
\hline 7 & 8.6 & 7 & 0.0039 & $0.153,0.124$ \\
\hline
\end{tabular}

The Royal Society of Chemistry apologises for these errors and any consequent inconvenience to authors and readers.

\footnotetext{
${ }^{a}$ Department of Chemistry, American University of Beirut, Beirut 1107-2020, Lebanon. E-mail: bilal.kaafarani@aub.edu.lb

${ }^{b}$ NanoTecCenter Weiz Forschungsgesellschaft mbH, Franz-Pichler-Straße 32, A-8160 Weiz, Austria

${ }^{c}$ Department of Biology \& Chemistry, New Mexico Highlands University, Las Vegas, NM 87701, USA

${ }^{d}$ Department of Chemistry and Center for Photochemical Sciences, Bowling Green State University, Bowling Green, Ohio, 43403, USA

${ }^{e}$ Department of Natural Sciences, Lebanese American University, Byblos, Lebanon. E-mail: brigitte.wex@lau.edu.lb

${ }^{f}$ Solar \& Photovoltaics Engineering Research Center, Physical Science and Engineering Division, King Abdullah University of Science \& Technology, Thuwal 23955-690o, Kingdom of Saudi Arabia

${ }^{g}$ Institute of Solid State Physics, Graz University of Technology, A-8010 Graz, Austria
} 